\title{
CONVERSANDO CON VIRGILIO EN EL SIGLO XIX. UN TESTIMONIO DE LA RECEPCIÓN DE LA BUCÓLICA $V$ EN LA MOD $A$ (ARGENTINA, 1837-1838)
}

\section{Conversing with Virgil in the 19th Century. A Testimony of the Reception of Eclogue V in La Moda (Argentina, 1837-1838)}

\author{
Luis Marcelo Martino* \\ Universidad Nacional de Tucumán
}

Palabras clave

Virgilio;

Bucólica V;

recepción;

Tradición Clásica

Keywords

Virgil;

Eclogue V;

reception;

Classical Tradition

\section{Resumen}

E1 10 de marzo de 1838 se publica en las páginas de La Moda. Gacetín semanal de Música, de Poesía, de Literatura, de Costumbres un artículo titulado "La conversación", atribuido a Juan María Gutiérrez. Para ejemplificar las bondades y rasgos de la conversación, el crítico argentino recurre a algunas imágenes, comparaciones, referencias literarias y citas, entre las que se destaca una perteneciente a Virgilio. Sin especificar la fuente concreta, Gutiérrez transcribe un breve pasaje en español, en prosa, que constituye a nuestro entender un testimonio valioso de la recepción de Virgilio en la literatura argentina. El presente trabajo se propone analizar dicha cita $\mathrm{y}$ las operaciones que implementa Gutiérrez para ponerla en diálogo con el nuevo contexto. 


\section{Conversando con Virgilio en el siglo XIX. Un testimonio de la recepción de la Bucólica V en La Moda (Argentina, 1837-1838) ${ }^{1}$}

La crítica literaria de todas las épocas le ha dedicado innumerables páginas a la cuestión de la influencia de Virgilio en Hispanoamérica y en Argentina, más concretamente. "Virgilio en América" se titula precisamente un ensayo de Juan María Gutiérrez publicado en la Revista del Río de la Plata (1875), que comienza de la siguiente manera: "Podría formarse un precioso volumen, titulado Virgilio en América, reuniendo las traducciones e imitaciones en lengua castellana que del gran poeta latino han ensayado varios humanistas hijos del nuevo mundo" (1875, p. 593). ${ }^{2}$ Unos años atrás, al ocuparse de la vida y obra de Juan Cruz Varela -responsable de una traducción parcial de la Eneida-, el crítico había afirmado que "Pocos son los que están al cabo de la influencia virgiliana en nuestra literatura poética [en referencia a la argentina], toda ella clásica y latina desde la 'Oda al Río Paraná' hasta el 'Canto a Ituzaingó”' (1871, p. 122). ${ }^{3}$ Gerardo Pagés, por su parte, le dedica al tema un frondoso estudio titulado "Virgilio en las letras argentinas. De Lavardén a Juan Cruz Varela" (1961), donde afirma que "Desde antiguo era Virgilio muy leído en estas tierras" (1961, p. 107). El crítico aclara que se propone en su trabajo "puntualizar simple y objetivamente las ocasiones en que la reminiscencia de Virgilio se ha concretado en un verso o en una alusión" (p. 108), ciñéndose a sus "imitaciones o reminiscencias en poetas éditos" (p. 109). Casi los mismos términos -imitaciones y reminiscencias- había empleado pocos años atrás Raymond L. Grismer, en su "Introduction to the classical influence on the literatures of Spain and Spanish America (A bibliographical study)" (1949), al referirse a la influencia de Virgilio en Europa y América: "Even an exhaustive list of studies on the subject fails to reveal the thousands of reminiscences and imitations of single lines and longer passages from Virgil's Bucolics, Georgics and Aeneid' (1949, p. 437-438).

Los trabajos arriba citados se inscriben por derecho propio en los estudios de la Tradición Clásica. La tarea de esta disciplina es definida por Vicente Cristóbal de manera abarcadora:

El estudio de la tradición clásica, por tanto, debe atender legítimamente a todo lo relativo a la perduración de cualquier elemento de las civilizaciones clásicas griega y latina, comprendiéndose como objeto de dicha disciplina no sólo la reelaboración o uso de tales elementos, sino también su mera conservación. (2005, p. 30)

En este proceso de transmisión de elementos grecolatinos a lo largo del tiempo juegan un rol fundamental las instancias de recepción de dichos elementos, como se desprende de la definición de Cristóbal. Si bien ambas categorías, recepción y Tradición Clásica, se han empleados indistintamente en algunos contextos, como señala Francisco García Jurado, "la recepción parece haberse constituido,

1. El equipo de Cuadernos de Literatura, después de haber sido aprobado en ronda de referato, hizo la revisión final de este artículo, publicado a modo de homenaje, por el reciente fallecimiento de su autor, Luis Marcelo Martino.

2. En este trabajo hemos optado por modernizar la ortografía de todas las citas de textos del siglo XIX.

3. Gerardo Pagés cuestionará varios años más tarde las bases que sustentan este juicio de Gutiérrez: “¿Lástima grande que él mismo no emprendiese en forma orgánica la tarea de fundamentar su afirmación!” (1961, p. 109). 
sobre todo en el ámbito anglosajón, en un estudio complementario, aunque diferente, del de la tradición clásica” (2015, p. 89). Hardwick y Stray (2008, p. 1) optan por emplear el término en plural, al que definen como "By 'receptions' we mean the ways in which Greek and Roman material has been transmitted, translated, excerpted, interpreted, rewritten, re-imaged and represented". Este enfoque nos resulta particularmente atractivo, ya que especifica y contempla de manera rica y abarcativa el abanico de posibilidades de recepción y reelaboración de un texto clásico.

\section{Unos versos de Virgilio}

Entre el 18 de noviembre de 1837 y el 21 de abril de 1838 se publica en Buenos Aires La Moda. Gacetín semanal de Música, de Poesía, de Literatura, de Costumbres, en el que colaboran algunos integrantes de la llamada "generación del 37", tales como Juan Bautista Alberdi, Juan María Gutiérrez, Demetrio y Jacinto Rodríguez Peña, Carlos Tejedor, Carlos Eguía y Vicente Fidel López, entre otros. ${ }^{4}$

El número 17 del gacetín, correspondiente al 10 de marzo de 1838, se abre con un artículo titulado "La conversación". Como la mayoría de los textos de La Moda, este no lleva firma. La identificación de sus autores, según señala Oría, se ha realizado en base a fuentes diversas. Este estudioso, responsable de la edición facsimilar de 1938, considera que una de estas fuentes, las anotaciones manuscritas (se supone, de Andrés Lamas) en el ejemplar de la Biblioteca Enrique Peña, debe considerarse fidedigna (1938, p. 215). La anotación correspondiente al artículo que nos ocupa establece que su autor es Juan María Gutiérrez.

"La conversación” comienza con una breve caracterización elogiosa de su objeto:

La más sencilla y general manera de comunicar el pensamiento y los afectos, como también la más humilde, es la conversación; ella es una necesidad que nace de la perfección del estado social, y una fuente de placeres para el hombre culto, que estima y ama a sus semejantes. (p. 1, col.1)

Tras revisar una serie de estereotipos sobre la idiosincrasia de determinadas naciones y pueblos europeos, Gutiérrez afirma, en concordancia con la opinión común ("Todos convienen"), que "sólo los franceses han hecho de la conversación un arte"(p.1, col.1). El artículo concluye con el establecimiento, no exento de ironías, de algunos principios que deben regir la conversación (no monopolizar el uso de la palabra ni pecar de pedantería, por ejemplo).

A lo largo del artículo, Gutiérrez apela a imágenes, comparaciones, citas y referencias literarias para exponer sus ideas acerca del tema. Hay que tener presente, en este sentido, que La Moda era una publicación concebida, en teoría, para un público no ilustrado ni erudito. Al argumentar sobre la opinión generalizada de que los franceses dominan el arte de la conversación -a diferencia de los alemanes, los ingleses y los italianos-, el autor inserta una cita, cuyo análisis constituye el objeto del presente trabajo.

4. Hasta la fecha se han publicado dos reediciones facsimilares de La Moda: la primera en 1938, a cargo de la Academia Nacional de la Historia, con prólogo y notas de José A. Oría, y la segunda editada por la Biblioteca Nacional de la República Argentina en 2011, con prólogo de Alberto M. Perrone. 
Las "buenas dotes sociales” y los defectos de los franceses, afirma Gutiérrez, explican por qué este pueblo se distingue en la conversación. Entre aquellas "dotes sociales", el autor menciona "la facilidad en concebir y alcanzar las relaciones que tienen los objetos entre sí, la facultad de observarlo todo de una sola mirada, y de experimentar y transmitir con rapidez los afectos e impresiones más opuestas" (p. 1, col. 2). Estos "son los elementos de que se compone el carácter francés, y constituyen la esencia del arte de la conversación" (p. 1). A continuación, sin mediar más que un punto seguido, Gutiérrez inserta la cita en cuestión, con la que concluye el párrafo y el tópico tratado:

A la conversación pueden aplicarse estos versos de Virgilio: "no le agrada ni el susurro apenas oído de los vientos al medio día, ni el ruido sordo de las olas que se quebrantan en las rocas, ni el hórrido estruendo de los torrentes que se despeñan entre lechos de ásperas piedra”. (p. 1, col. 2)

Gutiérrez no proporciona sobre el pasaje citado más datos que el de su autor, Virgilio. Cabe traer a colación aquí, una vez más, que la intención del gacetín es alcanzar a un público amplio para transmitirle de manera amena nociones de filosofía, política, arte, etc. ${ }^{5}$ Indicar la ubicación exacta del pasaje, proporcionando los datos sobre la obra de la que fue extraído y otros más detallados (canto, libro, versos), no contribuirán al propósito de la publicación, pudiendo, por el contrario, constituir un escollo en la lectura, prevista idealmente como ligera y placentera.

Un breve rastreo permite identificar la procedencia de la cita: se trata de los versos 82-84 de la bucólica V. Esta composición recrea la amable contienda entre los pastores Mopso y Menalcas, en cuyos cantos se narra la muerte, apoteosis y culto de Dafnis, personaje de particular importancia para el género pastoril. Como es sabido, al poema se le ha atribuido una importancia fundamental en la arquitectura del conjunto de las diez bucólicas, ya que se ubica en el centro de la obra (Camarero, 1983, p. 13-14; Martínez Astorino, 2006, p. 98). Por otra parte, la crítica se ha ocupado profusamente de la cuestión de la identificación de la figura de Dafnis, proponiendo interpretaciones alegóricas que han detectado que el pastor podría identificarse con Julio César, interpretación que parte de los comentarios de Servio. No es nuestra intención enumerar ni desarrollar exhaustivamente las innumerables interpretaciones que ha ofrecido la crítica especializada a lo largo del tiempo, pero sí nos parece interesante traer a colación sucintamente al menos dos de estas propuestas, como testimonios del interés suscitado por esta bucólica.

En su artículo titulado “E1 Dafnis de Virgilio” (1983), María Luisa Acuña realiza un estudio pormenorizado del poema, para plantear una interpretación religiosa: "La Bucólica $V$ señala la felicidad del hombre en la contemplación de dios" (1983, p. 40-41). La estudiosa adhiere a estudios especializados de la época, como el de Pierre Boyancé, que prefieren ver en Dafnis "la personificación de la alta dignidad del poeta y el don maravilloso que lo transforma, la inspiración” (p. 34). Descarta explícitamente, de este modo, la identificación entre Dafnis y Julio César: "Creemos difícil que Virgilio hubiera escrito esta espléndida composición pensando en Julio César” (p. 40). Varios años más tarde,

5. En el prospecto de La Moda, publicado en su primer número, se especifica que la publicación contendrá, entre otros asuntos, "Nociones claras y breves, sin metafísica, al alcance de todos, sobre literatura moderna, sobre música, sobre poesía, sobre costumbres, y muchas otras cosas cuya inteligencia fácil cubre de prestigio y de gracia la educación de una persona joven" (La Moda, N 1, 18/11/1837, p. 1, col. 1). 
echando mano de otras herramientas metodológicas, Pablo Martínez Astorino, en su texto "Dafnis en la bucólica V de Virgilio: la alusión compleja y los límites de la identidad" (2006), concentra su interés en la figura del célebre pastor, dejando claro desde el principio que la cuestión de su identificación ha ocupado a la "ciencia filológica" desde sus comienzos (2006, p. 89). La propuesta de Martínez Astorino, que se nutre de la numerosa bibliografía sobre el tema, desestima una lectura en clave exclusivamente alegórica de la figura de Dafnis en esta égloga, y se inclina por una interpretación integral y compleja, que contemple distintas evocaciones y significados de este personaje. Dafnis aludiría entonces, de manera no excluyente, a tres figuras: un "salvador de la humanidad" (p. 93), "el pastor ideal que realiza plenamente la vida bucólica inaugurando una edad de oro”(p. 95) y Julio César. Como resulta evidente, la postura de Acuña se aproximaría a la segunda alusión.

La cita de la bucólica V que Gutiérrez recupera, traducida y adaptada, corresponde a los versos 82-84, puestos en boca de Mopso:

nam neque me tantum venientis sibilus Austri nec percussa iuvant fluctu tam litora, nec quae saxosas inter decurrunt flumina valles.

El pasaje ocupa, podría decirse, un lugar marginal dentro del poema. El canto sobre Dafnis ya ha concluido. Los versos indicados pertenecen a la intervención de Mopso en la que este discurre acerca de los dones que le entregará a Menalcas por su canto. Gutiérrez descarta de esta intervención el primer verso (Quae tibi, quae tali reddam pro carmine dona?, v. 81), y ofrece, como vimos, una traducción al español sobre la que vale la pena detenerse. Una primera cuestión que se plantea es establecer la procedencia de dicha versión. ¿Se trata de una traducción realizada por el propio Gutiérrez? Si no fuera así, ¿de qué edición la habría tomado? Nuestra investigación no ha podido responder con absoluta certeza a estos interrogantes. Solo podemos arriesgar algunas hipótesis explicativas. En primer lugar, cabe recordar que Gutiérrez emitió opiniones, en algunas de sus obras, que dejan entrever su conocimiento del latín y del arte de su traducción. En su estudio sobre la vida y obra de Juan Cruz Varela, el crítico se ocupa de la labor de este como traductor del latín. Al analizar la traducción al español que aquel realiza de la oda I, XV de Horacio, Gutiérrez compara esta versión con la imitación del poema a cargo de Fray Luis de León: "Varela al traducir este relámpago de inspiración le ha interpretado con menos felicidad que el imitador” (1871, p. 104). Tras señalar algunos puntos cuestionables de la versión de Varela -la elección del octosílabo español, "inadecuado para la oda” (p. 104)-, afirma que "A pesar de aquellos inconvenientes levantados tal vez de propósito para tener la honra de superarlos, hay trozos en esta traducción que remedan el movimiento y el vuelo horaciano" (p. 104). El crítico acompaña su elogio con una transcripción de algunos versos en latín de la oda, acompañados por la correspondiente traducción de Varela, para que el lector pueda valorar por sí mismo los méritos de su versión (p. 105-106). Estos juicios revelan que Gutiérrez poseía los conocimientos suficientes de la lengua latina para encarar una traducción al español. Por otra parte, cabe recordar que Varela le había enviado a Gutiérrez una copia de su traducción de los primeros libros de la Eneida, ${ }^{6}$ lo que revelaría

6. "sin tener la honra de conocerle personalmente [Juan Cruz Varela] nos favoreció desde Montevideo, el año 1835, con varias cartas amistosas y entre ellas con una a la cual se dignó acompañar una copia autógrafa y esmerada de su traducción de los primeros libros de la Eneida; presente delicado que conservamos entre los objetos de nuestro mayor aprecio" (Gutiérrez, 1871, p. 4). 
que lo consideraba un árbitro calificado en la materia. Pagés destaca del crítico, a su vez, entre otros rasgos, "su seria preparación y amor por los clásicos" (p. 109). Si bien no nos consta que Gutiérrez haya traducido obras latinas al español, este hecho no constituye un obstáculo para que el crítico, dotado de los rudimentos necesarios -si nos guiamos por sus palabras y juicios-, haya traducido él mismo los versos de la bucólica $V$ que incluye en su artículo.

La segunda hipótesis, que contempla la posibilidad de que Gutiérrez haya recurrido a una traducción ajena, es, por otra parte, también verosímil. La obra virgiliana estaba disponible en varias ediciones en la Buenos Aires de la época, y circulaba por las librerías y salones de lectura. Uno de esos espacios de circulación privilegiada de bienes culturales es el "Gabinete de Lectura o Biblioteca pública”, inaugurado por Marcos Sastre a comienzos de 1835, en la librería que poseía en Buenos Aires desde 1833. La prensa de la época (La Gaceta Mercantil y el Diario de la Tarde) publica un aviso el 22 de enero donde se anuncia la inauguración y se detalla el material que será puesto a disposición de los lectores. El aviso contiene una larga lista de autores, agrupados en su mayoría según un criterio disciplinar (agricultura, filosofía, botánica, química, economía). No obstante, en un pasaje del aviso se realiza una breve discriminación en función del carácter moderno o antiguo/clásico de los autores disponibles:

Aunque hay otros muchos célebres políticos modernos, pero como se han multiplicado tanto en el día las ediciones de sus obras, me ha parecido innecesario colocarlos en mi Biblioteca. No sucede así con las buenas versiones de los clásicos griegos y latinos, que son tan raras entre nosotros; y por lo mismo se encontrarán en el Gabinete las mejores traducciones de las obras de Virgilio, Horacio, Cicerón, Séneca, Salustio, Tito Livio, César, Valerio Máximo, Nepote, Demóstenes, Isócrates, Lisias y otros. (Weinberg, 1977, p. 41)

El pasaje citado es un testimonio valioso de la escasa disponibilidad de "buenas versiones" de las obras grecolatinas, pero también de la presencia en la biblioteca de Sastre de "las mejores traducciones" de algunas de estas obras. Con respecto a Virgilio, no se especifica cuáles están disponibles en el gabinete.

Otra fuente que ofrece información útil para nuestro propósito son los anuncios publicados en los periódicos por las librerías, ofreciendo el material disponible para la venta. Un estudio de Sandra Liliana Díaz identifica, en base al análisis de los avisos aparecidos en La Gaceta Mercantil, "cuáles eran los autores de la antigüedad clásica cuyas obras se ofrecían a los lectores contemporáneos entre 1830 y 1852" (2003, p. 127). Díaz constata que Buenos Aires contó en ese período "con un volumen modesto de obras de autores clásicos en oferta" (p. 129), y que Virgilio estaba entre los más asiduamente ofertados, junto con Cicerón y Horacio (p. 131). Si bien la estudiosa aclara que "en la mayoría de los casos La Gaceta Mercantil explicita el nombre del autor y no el de la obra” (p. 127), es posible identificar ediciones concretas de la pieza de Virgilio que nos interesa: las Bucólicas. Gracias al invalorable listado que ofrece Díaz en orden alfabético de autores griegos y latinos mencionados en los avisos de La Gaceta Mercantil, con datos precisos de número del periódico, fecha, página y columna, pudimos constatar que la librería de Marcos Sastre (ubicada en calle Reconquista 54) ofrece el 3 de 
abril de 1834 "Las Eclogas y las Geórgicas de Virgilio, traducidas al castellano, por Fr. Luis de León, Velazco y Juan de Guzmán” (La Gaceta Mercantil, Nº3252, 3/4/1834, p. 1, col. 3).7

De las traducciones mencionadas, solo la de Fray Luis de León (1631) abarca las diez églogas virgilianas. Hernández de Velazco traduce únicamente las églogas I y IV, piezas incluidas en su edición de la Eneida (1574) (Menéndez Pelayo, 1879, p. XXIII), mientras que Juan de Guzmán solo ofrece una versión de la bucólica X, en su edición de las Geórgicas (1586) (Menéndez Pelayo, p. XXIV), según registra Marcelino Menéndez Pelayo en su estudio consagrado a los "Traductores de las Églogas y las Geórgicas de Virgilio”. Un cotejo de la versión de Fray Luis de León, la única edición completa de las mencionadas, con el pasaje del artículo de La Moda permite descartarla como la fuente empleada.

Resulta difícil, entonces, establecer con precisión de qué edición concreta de las bucólicas habría extraído Gutiérrez los versos citados, en el caso de que no hubieran sido traducidos por él mismo. Las obras grecolatinas presentes en los catálogos de las librerías que se ofertan en la prensa, como ya lo había constatado Díaz, aparecen por lo general englobadas en una mención general del autor. Esta fuente, por lo tanto, no ofrece mayores evidencias para nuestra indagación.

No queremos abandonar esta cuestión sin reiterar el conocimiento panorámico de Gutiérrez de las adaptaciones de las obras de Virgilio por poetas americanos, como queda testimoniado en su estudio "Virgilio en América", citado al comienzo de este trabajo. En este mismo artículo, menciona la traducción de Eugenio de Ochoa y confiesa que ha leído las Églogas, las Geórgicas y los cuatro primeros libros de la Eneida traducidos por Miguel Antonio Caro (1875, p. 610). Estas traducciones son realizadas entre 1861 y 1875 (Aurelio Espinosa Pólit, 1955-56, p. 76), con posterioridad, por lo tanto, a la época en que se publica La Moda.

Por otra parte, en un pasaje inicial de su estudio sobre Varela, el crítico ejemplifica con la bucólica I la inmortalidad que alcanzará la obra de Juan Cruz Varela: "La Primera Égloga del Cisne de Mantua, recomendará eternamente a Octavio ante el corazón de la humanidad, cuando ni polvo quede del bronce de sus estatuas y medallas" (1871, p. 9). Con este símil, y apelando además al motivo de la inmortalidad de la obra poética -no podemos dejar de evocar los versos iniciales de la oda III, 30 de Horacio, Exegi monumentum aere perennius-, Gutiérrez pretende reivindicar la memoria de Varela y reparar el daño que este había sufrido y el olvido en el que habría caído tras ser desterrado en 1829.

\section{Una cita distorsionada}

El análisis de la operación de citado que realiza Gutiérrez reviste, a nuestro entender, una importancia significativa, más allá de quién sea el autor de la traducción del poema al que pertenecen los versos insertados en el artículo. Podríamos decir, en primer lugar, que esta operación consta básicamente de una descontextualización y una recontextualización. Gutiérrez extrae unos versos de la totalidad de un texto en el que tenían un sentido y lo inserta en un nuevo texto (el artículo de $L a$ Moda), estableciendo un diálogo con el nuevo contexto, diálogo inédito y no previsto, en principio,

7. El mismo anuncio se publica en La Gaceta Mercantil N 3258, correspondiente al 10 de abril de 1834. 
por el texto original, es decir, el texto del que fue tomado el pasaje. Esta operación es semejante a la que realiza un/a autor/a al seleccionar un fragmento de otro texto para colocarlo como epígrafe de una obra propia. Este gesto le permite al texto tomado como epígrafe instaurar sentidos nuevos y establecer nuevas relaciones, sentidos y relaciones guiados y controlados por el responsable de la descontextualización / recontextualización.

Un problema adicional, en nuestro caso, es el del texto original, es decir, el texto marco del cual fueron tomados los versos. Dicho texto sería una versión al español de un texto en latín, que, en rigor, deberíamos llamar el original. Ahora bien, como vimos, resulta difícil establecer si estamos en presencia de una traducción realizada por el propio Gutiérrez, o bien si este recurre a alguna edición en español de la bucólica V. En caso de que la primera opción fuera la correcta, podríamos pensar que, tal vez, Gutiérrez tradujo solamente esos versos, no la composición completa, y con la única finalidad de insertarlos en su artículo. En este caso, ¿podríamos hablar de la existencia de un texto original o marco, al no formar parte los versos citados de una versión completa?

Analicemos ahora, concretamente, cómo realiza el crítico la mencionada recontextualización. La primera decisión que toma es la de incluir los versos traducidos, en lugar de ponerlos en latín, decisión que, a nuestro juicio, está motivada por el tono del gacetín y el público amplio al que pretende dirigirse. No es la intención demostrar aquí erudición, con la inclusión de un texto en una lengua inaccesible para un lector medio. Por este mismo motivo, tampoco tendría sentido incluir los versos en latín acompañados de su traducción al español. Los lectores preconfigurados por la publicación no estarían en principio en condiciones de cotejar ambas versiones y de juzgar sobre los méritos de la traducción. Cuando Gutiérrez incluye versos en latín de la oda I, XV de Horacio, caso que mencionamos más arriba, lo hace en un estudio de marcado carácter erudito. La segunda decisión que toma el crítico es inclinarse por la prosa a la hora de incluir el pasaje citado, pese a que el original latino está en versos. En este caso se aplicarían, a nuestro juicio, los mismos motivos señalados para la primera decisión.

Sin dejar de lado las salvedades y cautelas ya establecidas que presupone afirmar la existencia de un texto original, podríamos decir que Gutiérrez realiza una manipulación y deformación semántica interesada del pasaje, operaciones válidas y que entrarían perfectamente dentro de las atribuciones y licencias que un/a autor/a puede tomarse, como ya lo dijimos al hablar de los epígrafes, sobre todo en un texto que no se pretende especializado ni erudito. La primera manipulación que realiza el crítico consiste en cambiar el objeto de los sentimientos expresados en los versos de Virgilio: el pronombre personal de primera persona, me-cuyo referente es Mopso- del texto en latín es reemplazado por uno en tercera persona, "le". Esta operación tiene la finalidad de establecer concordancia gramatical con el referente del nuevo contexto, la conversación, a la que Gutiérrez personifica.

El segundo cambio significativo que introduce Gutiérrez es la eliminación de todo vestigio de la comparación presente en los versos del poema original, expresada por medio del adverbio tantum, palabra que, en una eventual traducción al español, está ausente del pasaje citado. Los elementos mencionados en los versos 82-84 de la égloga constituyen en realidad el segundo término de la comparación que establece Mopso, siendo el primero los versos recientemente cantados por Menalcas (pro tali carmine). Aquel confiesa que le provoca más placer el canto de este que algunos elementos 
de la naturaleza (selección que funcionaría de manera metonímica y representativa). Dado el alto valor que revisten tales elementos en una poesía de corte pastoril, la afirmación hiperbólica de Mopso contribuye a una exaltación suprema del canto de Menalcas. En otras palabras, a Mopso le agrada tanto el canto de su amigo que no duda en colocarlo en una posición superior en su ánimo a la que ocupan el viento austral, ${ }^{8}$ las olas y los ríos que corren entre los valles.

Ahora bien, al suprimir la comparación, Gutiérrez introduce un sentido inédito para unos versos de un poema pastoril. La afirmación de que a la conversación, ya no a Mopso, no le agradan el soplo del Auster, las costas castigadas por las olas y los ríos, pervierte el género bucólico e instaura un desvío deliberado con respecto al mismo. La conversación, podríamos decir glosando a Gutiérrez, no se siente a gusto ni se desarrolla en plenitud en las soledades de los campos, en medio de la naturaleza agreste. Necesita de la ciudad y de sus espacios de sociabilidad, como las tertulias. Como define Gutiérrez en su artículo, la conversación es "una necesidad que nace de la perfección del estado social” (p. 1, col. 1). E1 locus amoenus virgiliano se desplaza del campo a la ciudad, resignificándose.

\section{A modo de conclusión}

Dentro de las incontables muestras y fenómenos de recepción de los clásicos grecolatinos en la literatura y la cultura argentina $-\mathrm{y}$, en realidad, en cualquier literatura y cultura-, hay un sector, a nuestro juicio, que se encuentra por lo general invisibilizado: las menciones o citas breves, fragmentos de textos apenas -esas "single lines" que contempla Grismer-, aunque verdaderos textos ellos mismos, incluidos en las páginas de la prensa periódica. Estas manifestaciones tienden a pasar desapercibidas o son desdeñadas por los investigadores que persiguen los grandes casos de recepción, las obras clásicas traducidas o adaptadas. A este conjunto pertenece la cita virgiliana de la que nos hemos ocupado en el presente trabajo. Unos cuantos versos virgilianos son ¿traducidos ad hoc? ¿ ‘tomados de una traducción previa? y adaptados, con un sentido prácticamente contrario al del original latino. Las operaciones mencionadas por Hardwick y Stray, citados al comienzo de este trabajo, se revelan aquí de una manera nítida: extractar, reescribir, reimaginar. El gesto de Gutiérrez en La Moda se inscribiría entonces con pleno derecho en ese linaje de reminiscencias de Virgilio, para emplear el término de Grismer y Pagés, reminiscencias que, en ocasiones, son tan tenues que se escapan a la vista de la crítica.

\section{Referencias bibliográficas}

Acuña, M. L. (1983). El Dafnis de Virgilio. Cuadernos de Literatura. Revista de Estudios Lingüísticos y Literarios, 2, 31-43. https://bit.ly/2WPaWHV.

Buisel, M. D. (1996). ¿Por qué Auster? Auster, 1, 13-14.

Camarero Benito, A. (1983). Reflexiones en el bimilenario de Virgilio. Cuadernos de Literatura. Revista de Estudios Lingüísticos y Literarios, 2, 9-20. https://bit.ly/3rQ4Nqv.

8. María Delia Buisel, al recoger testimonios de la mención del viento Auster, menciona el "austro virgiliano cuyo silbo encanta y arrebata a Mopso" del verso 82 de la Bucólica V (1996, p. 14). 
Cristóbal, V. (2005). Sobre el concepto de Tradición Clásica. En Signes Codoñer, J.; Antón Martínez, B.; Conde Parrado, P.; González Manjarrés, M. Á. e Izquierdo Izquierdo, J. A. (eds.), Antiquae lectiones. El legado clásico desde la Antigüedad hasta la Revolución Francesa (pp. 29-34). Madrid, Cátedra.

Díaz, S. L. (2003). La presencia de los autores de la antigüedad clásica a través de los avisos de $L a$ Gaceta Mercantil (1830-1852). En IV Congreso Argentino de Americanistas Año 2001 (tomo 1, pp. 127-158). Buenos Aires, Sociedad Argentina de Americanistas.

Espinosa Pólit, A. (1955-1956). Miguel Antonio Caro, intérprete de Virgilio. Thesaurus. Boletín del Instituto Caro y Cuervo, 11 (1-3), 75-92.

García Jurado, F. (2015). La metamorfosis de la Tradición Clásica, ayer y hoy. En Vela Tejada, J.; Fraile Vicente, J. F. y Sánchez Mañas, C. (eds.), Studia Classica Caesaraugustana. Vigencia y presencia del mundo clásico hoy: XXV años de Estudios Clásicos en la Universidad de Zaragoza (pp. 69-109). Zaragoza, Prensas de la Universidad de Zaragoza.

Grismer, R. L. (1949). Introduction to the classical influence on the literatures of Spain and Spanish America (A bibliographical study). Thesaurus. Boletin del Instituto Caro y Cuervo, 5 (1-3), 433-446.

Gutiérrez, J. M. (1871). Estudio sobre las obras y la persona del literato y publicista argentino D. Juan de la Cruz Varela. Buenos Aires, Imprenta y Librería de Mayo.

Gutiérrez, J. M. (1875). Virgilio en América. Revista del Río de la Plata, X (40), 593-631.

Hardwick, L. y Stray, C. (ed.) (2008). A Companion to Classical Receptions, Oxford, Blackwell.

Martínez Astorino, P. (2006). Dafnis en la bucólica V de Virgilio: la alusión compleja y los límites de la identidad. Auster, 10-11, 89-100.

Menéndez Pelayo, M. (1879). Traductores de las Églogas y las Geórgicas de Virgilio. En Virgilio. Églogas y Geórgicas traducidas en versos castellanos por D. Félix M. Hidalgo y D. Miguel Antonio Caro (pp. VII-LXXV). Madrid, Imprenta Central.

Oría, J. A. (1938). Notas. La Moda. Gacetín Semanal de Música, de Poesía, de Literatura, de Costumbres [reimpresión facsimilar publicada por la Academia Nacional de la Historia] (pp. 213-220). Buenos Aires, Kraft.

Pagés, G. H. (1961). Virgilio en las Letras Argentinas. De Lavardén a Juan Cruz Varela. Boletín de la Academia Argentina de Letras, XXVI (99), 105-165.

Weinberg, F. (1977). El Salón Literario de 1837. Con escritos de M. Sastre - J. B. Alberdi -J. M. Gutiérrez - E. Echeverría. Buenos Aires, Hachette. 
*Luis Marcelo Martino Licenciado y Doctor en Letras por la Universidad Nacional de Tucumán, Diplomado Superior en Ciencias Sociales con mención en Educación y Nuevas Tecnologías por la Facultad Latinoamericana de Ciencias Sociales (FLACSO), Profesor Adjunto en la Facultad de Filosofía y Letras de la Universidad Nacional de Tucumán. Investigador Adjunto del CONICET. Temas de investigación: "Posturas polémicas en la literatura y la prensa rioplatenses del siglo XIX".

RECIBIDO: 03/06/2021

Aceptado: 20/06/2021 